\title{
Static Decoupling Control Based on Hammerstein Model and Neural Network for Induction Motors
}

\author{
Mei Congli ${ }^{1}$, Yin Kaiting, Huang Wentao and Liu Guohai \\ School of Electronic and Information Engineering, Jiangsu University, Zhenjiang \\ 212013, China \\ 'clmei@ujs.edu.cn
}

\begin{abstract}
A novel static decoupling control strategy based on Hammerstein model and neural network for induction motors was proposed in this paper. Hammerstein model, consisting of a static nonlinear module and a dynamic linear module, can be used to model many nonlinear systems. In the proposed method, firstly, neural network and auto-regressive moving-average (ARMA) model were employed to construct the static nonlinear module and the dynamic linear module respectively. Further, neural network inverse model of the static nonlinear module can be trained on the static dataset collected in the framework of the Hammerstein model. Finally, the inverse model was utilized to offset the nonlinear characteristic of an induction motor, decoupled into a rotor speed subsystem and a rotor flux subsystem. Simulations show that the proposed static decoupling control strategy has satisfactory decoupling performances and robustness to load disturbance in close loop control.
\end{abstract}

Keywords: Induction motor; Static decoupling control; Hammerstein model; Neural network

\section{Introduction}

Induction motors are characterized by multivariable, nonlinear and strong coupling systems. Though they are with long history and widely used in modern industries, the high performance control problem has not been solved for their complexity.

Recently, many scholars still focused their work on advanced control methods for high performance control of induction motors, especially on decoupling control. Chan et al. designed the adaptive decoupling control system of induction motors based on model reference adaptive control theory. The desired robustness and stability can be obtained by adjusting the controller parameters according to the changes of plant parameters based on adaptive algorithms[1]. Kawabata et al. developed the state-equation and block diagram of an induction motor using a matrix method based on the vector control method. In the block diagram, all branches of summing points have physical interpretation, and the design of decoupling controller become transparent and easy[2]. John Chiasson improved the use of dynamic state feedback to achieve feedback linearization of induction motors. The 6th-order nonlinear dynamical model was transformed to 3rd-order decoupled linear systems by the nonlinear state feedback method with stator input voltages[3]. However, the controller was still complex and difficult to be realized for heavy burden of calculation. In [5-8], static neural networks(NNs) based ath-order inversion[4] was employed to realize decoupling control for nonlinear mapping ability of NNs. The decoupling control of induction motors based on NN inversion was proposed in[6]. In the work, an induction motor was decoupled into a rotor speed subsystem and a rotor flux subsystem in cascade with a static $\mathrm{NN}$ and four 
integrators. However, this method is sensitive to inputs and the outputs may change abruptly for its aim of high dynamic performance of decoupling control.

To overcome the above-mentioned problems, a static decoupling control method of induction motors based on Hammerstein model[9] and NN was proposed in this paper. A Hammerstein model, consisting of a static nonlinear module and a dynamic linear module, was widely used in the field of nonlinear system modeling. In the proposed method, the auto-regressive moving-average (ARMA) model and online NN learning method were adopted to construct the linear dynamic module and the nonlinear static module respectively. In this method, the latter is the inversion of static nonlinearity of an induction motor and can be trained using NN on static dataset collected in the framework of Hammerstein model. Simulations show that the proposed strategy has high decoupling performance and robustness with load disturbance.

\section{Invertibility Analysis of Induction Motor Model}

\subsection{Induction Motor Model}

An induction motor, with input voltage $u_{\mathrm{sm}}$ and $u_{\mathrm{st}}$ in two-phase rotating coordinate, powered by a PWM voltage source inverter was shown in Figure 1. If the nonlinear delay time of the inverter, the magnetic saturation and iron loss of induction motors are ignored, the mathematic model of the induction motor system can be formulated as 4th-order state equations in two-phase rotating coordinate as equation (1)[10].

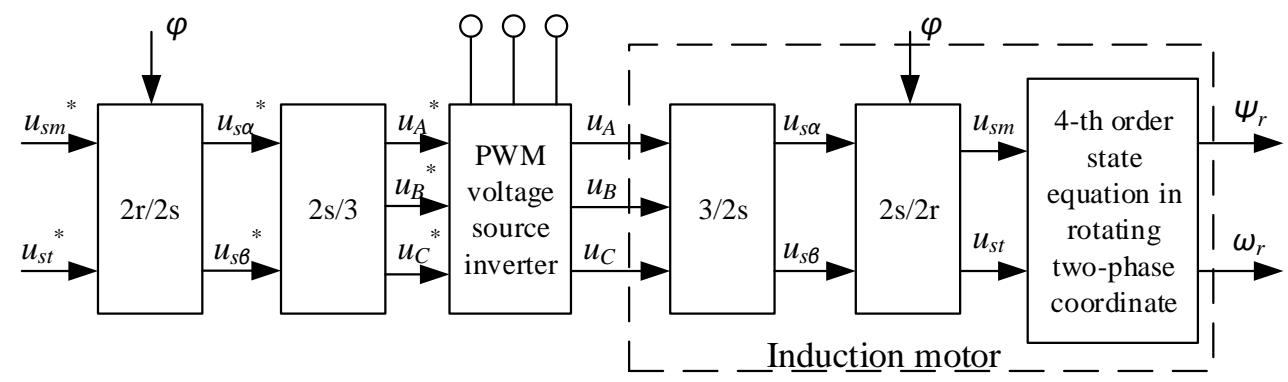

Figure 1. Schematic Diagram of Induction Motors Powered By a Voltage Source Inverter

$$
\left\{\begin{array}{l}
\frac{\mathrm{d} i_{s m}}{\mathrm{~d} t}=-\left(\frac{L_{m}{ }^{2} R_{r}+L_{r}^{2} R_{s}}{\sigma L_{s} L_{r}^{2}}\right) i_{s m}+\left(\mathrm{n}_{\mathrm{p}} \omega_{\mathrm{r}}+\frac{L_{m} R_{r}}{L_{r} \psi_{r}} i_{s t}\right) i_{s t}+\frac{L_{m} R_{r}}{\sigma L_{s} L_{r}^{2}} \psi_{r}+\frac{u_{s m}}{\sigma L_{s}} \\
\frac{\mathrm{d} i_{s t}}{\mathrm{~d} t}=-\left(\mathrm{n}_{\mathrm{p}} \omega_{\mathrm{r}}+\frac{L_{m} R_{r}}{L_{r} \psi_{r}} i_{s t}\right) i_{s m}-\left(\frac{L_{m}{ }^{2} R_{r}+L_{r}{ }^{2} R_{s}}{\sigma L_{s} L_{r}^{2}}\right) i_{s t}-\frac{n_{p} L_{m} \omega_{\mathrm{r}} \psi_{r}}{\sigma L_{s} L_{r}}+\frac{u_{s t}}{\sigma L_{s}} \\
\frac{\mathrm{d} \psi_{r}}{\mathrm{~d} t}=\frac{L_{m} R_{r}}{L_{r}} i_{s m}-\frac{R_{r}}{L_{r}} \psi_{r} \\
\frac{\mathrm{d} \omega_{\mathrm{r}}}{\mathrm{d} t}=n_{p}\left(\frac{L_{m}}{J L_{r}} i_{s t} \psi_{r} n_{p}-\frac{T_{l}}{J}\right)
\end{array}\right.
$$

where $i, \Psi, u, R$ and $\omega$ are current, flux, voltage, resistance and rotor speed respectively. Subscripts $s$ and $r$ denote stator and rotor respectively. $m$ and $t$ represent the two vertical components in rotor flux coordinate. $L_{m}, L_{s}$ and $L_{r}$ are 
mutual inductance, stator inductance and rotor inductance respectively. $n_{p}$ is the number of pole-pairs. And $J$ denotes rotary inertia[6].

\subsection{Invertibility Analysis}

In equation (1), the state variable is $\mathbf{x}=\left[x_{1}, x_{2}, x_{3}, x_{4}\right]^{\mathrm{T}}=\left[i_{s m}, i_{s t}, \psi_{r}, \omega_{r}\right]^{\mathrm{T}}$, the input is $\mathbf{u}=\left[u_{1}, u_{2}\right]^{\mathrm{T}}=\left[u_{s m}, u_{s t}\right]^{\mathrm{T}}$, and the output is $\mathbf{y}=\left[y_{1}, y_{2}\right]^{\mathrm{T}}=\left[x_{3}, x_{4}\right]^{\mathrm{T}}=\left[\psi_{\mathrm{r}}, \omega_{\mathrm{r}}\right]^{\mathrm{T}}$. Then, equation (1) can be rewritten as:

$$
\left\{\begin{array}{l}
\frac{\mathrm{d} x_{1}}{\mathrm{~d} t}=-\gamma x_{1}+\left(\mathrm{n}_{\mathrm{p}} x_{4}+\frac{L_{m} \eta}{x_{3}} x_{2}\right) x_{2}+\beta \eta x_{3}+\frac{u_{1}}{\sigma L_{s}} \\
\frac{\mathrm{d} x_{2}}{\mathrm{~d} t}=-\left(\mathrm{n}_{\mathrm{p}} x_{4}+\frac{L_{m} \eta x_{2}}{x_{3}}\right) x_{1}-\gamma x_{2}-n_{p} \beta x_{3} x_{4}+\frac{u_{2}}{\sigma L_{s}} \\
\frac{\mathrm{d} x_{3}}{\mathrm{~d} t}=L_{m} \eta x_{1}-\eta x_{3} \\
\frac{\mathrm{d} x_{4}}{\mathrm{~d} t}=n_{p}\left(\mu x_{2} x_{3}-\frac{T_{l}}{J}\right)
\end{array}\right.
$$

Where $\eta=\frac{R_{r}}{L_{r}}, \beta=\frac{L_{m}}{\sigma L_{s} L_{r}}, \gamma=\frac{L_{m}^{2} R_{r}+L_{r}^{2} R_{s}}{\sigma L_{s} L_{r}^{2}}, \mu=n_{p} \frac{L_{m}}{J L_{r}}$, and $\sigma=1-\frac{L_{m}{ }^{2}}{L_{s} L_{r}}$.

To analyze the invertibility of an induction motor system, the output $\mathbf{y}=\left[y_{1}, y_{2}\right]^{\mathrm{T}}$ should be derivated as follows[4].

$$
\begin{gathered}
y_{1}^{(1)}=\eta L_{m} x_{1}-\eta x_{3} \\
y_{1}^{(2)}=\eta L_{m}\left[-\gamma x_{1}+\left(\mathrm{n}_{\mathrm{p}} x_{4}+\frac{x_{2}}{x_{3}} L_{m} \eta\right) x_{2}+\right. \\
\left.\mu \beta x_{3}+\frac{u_{1}}{\sigma L_{s}}\right]-\eta^{2}\left(L_{m} x_{1}-x_{3}\right) \\
y_{2}^{(1)}=n_{p}\left(\mu x_{2} x_{3}-\frac{T_{l}}{J}\right) \\
y_{2}^{(2)}=n_{p} \mu x_{3}\left[-\left(\mathrm{n}_{\mathrm{p}} x_{4}+\frac{\eta L_{m}}{x_{3}}\right) x_{1}-\gamma x_{2}\right. \\
\left.-n_{p} \beta x_{3} x_{4}+\frac{u_{2}}{\sigma L_{s}}\right]-n_{p} \mu \eta x_{2}\left(L_{m} x_{1}-x_{3}\right)
\end{gathered}
$$

Obviously, the input $\mathrm{u}$ is visualized in the output equation after twice differentiation. The inputs in equation (4) and equation (6) should be derivated as equation (7) to satisfy the reversible condition.

$$
\partial y_{i}^{(\mathrm{k})} / \partial u_{j}=0(j=1,2 ; i=1,2 ; k=0,1)
$$

then

$$
\mathbf{A}(x)=\left[\begin{array}{ll}
\frac{\partial y_{1}^{(2)}}{\partial u_{1}} & \frac{\partial y_{1}^{(2)}}{\partial u_{2}} \\
\frac{\partial y_{2}{ }^{(2)}}{\partial u_{1}} & \frac{\partial y_{2}{ }^{(2)}}{\partial u_{2}}
\end{array}\right]=\left[\begin{array}{cc}
\frac{\eta L_{m}}{L_{s} \sigma} & 0 \\
0 & \frac{\mu x_{3}}{L_{s} \sigma}
\end{array}\right]
$$

$\operatorname{det}(\mathbf{A}(x))=-\left(\eta \mu L_{m} / L_{s}^{2} \sigma^{2}\right) x_{3}$. Obviously, the rotor flux $x_{3}=\psi_{r} \neq 0, \operatorname{sodet}(\mathbf{A}(x)) \neq 0$. $\mathrm{A}(\mathrm{x})$ is nonsingular and $\operatorname{rank}[\mathrm{A}(\mathrm{x})]=2$. It means that the relative order of the induction motor system is $2(\alpha=2)$ and the system is invertible. 


\section{Static Decoupling Control of Induction Motors Based on Hammerstein Model and Neural Network}

\subsection{Hammerstein Model based Decoupling Control Strategy}

A typical structure of Hammerstein model, consisting of a static nonlinear module $N(\cdot)$ and a dynamic linear module $G(\mathrm{z})$ can be represented in Figure 2[11].

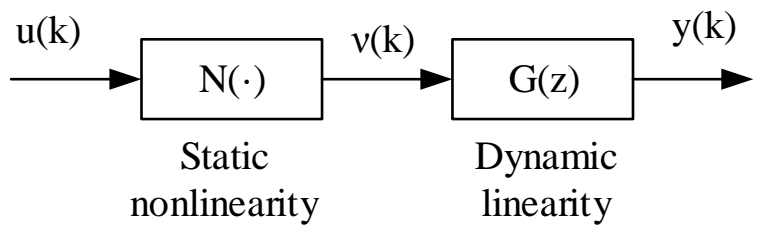

Figure 2. Structure of Hammerstein Model

In Figure 2, $u(\mathrm{k}), v(\mathrm{k})$ and $y(\mathrm{k})$ denote the input, internal and output signals at time $k$ respectively. The structure is widely used in modeling nonlinear dynamic systems. And the nonlinear induction motor model with two inputs and two outputs can also be formulated using Hammerstein model.

In the structure of Hammerstein model, the coupling characteristic is also in the dynamic linear module. A static decoupling matrix has been proposed to eliminate the coupling characteristic of linear MIMO systems[12]. Assume that the dynamic linear module $G(\mathrm{z})$ with two inputs and two outputs is:

$$
G(\mathrm{z})=\left[\begin{array}{ll}
g_{11}(\mathrm{z}) & g_{12}(\mathrm{z}) \\
g_{21}(\mathrm{z}) & g_{22}(\mathrm{z})
\end{array}\right]
$$

The static decoupling matrix $D$ is given by

$$
D=G^{-1}(0)=\frac{1}{\operatorname{det} G(0)}\left[\begin{array}{cc}
g_{22}(0) & -g_{12}(0) \\
-g_{21}(0) & g_{11}(0)
\end{array}\right]
$$

where $G(0)$ is nonsingular. The transfer function of the decoupled system is $Q(\mathrm{z})=$ $G(\mathrm{z}) D$ where

$$
\begin{aligned}
& q_{11}(\mathrm{z})=\frac{g_{11}(\mathrm{z}) \mathrm{g}_{22}(0)-\mathrm{g}_{12}(\mathrm{z}) \mathrm{g}_{21}(0)}{\operatorname{det} G(0)} \\
& q_{12}(\mathrm{z})=\frac{g_{12}(\mathrm{z}) \mathrm{g}_{11}(0)-\mathrm{g}_{12}(0) \mathrm{g}_{11}(\mathrm{z})}{\operatorname{det} G(0)} \\
& q_{21}(\mathrm{z})=\frac{g_{21}(\mathrm{z}) \mathrm{g}_{22}(0)-\mathrm{g}_{21}(0) \mathrm{g}_{22}(\mathrm{z})}{\operatorname{det} G(0)} \\
& q_{22}(\mathrm{z})=\frac{g_{22}(\mathrm{z}) \mathrm{g}_{11}(0)-\mathrm{g}_{21}(\mathrm{z}) \mathrm{g}_{12}(0)}{\operatorname{det} G(0)}
\end{aligned}
$$

It follows from the construction that $Q(0)$ is the identity matrix. A Taylor series expansion of the transfer function $Q(\mathrm{z})$ for small $\mathrm{z}$ gives

$$
Q(\mathrm{z}) \approx\left[\begin{array}{cc}
1 & k_{12} z \\
k_{21} z & 1
\end{array}\right]
$$

where $k_{12}$ and $k_{21}$ are constants. Hence, for low frequencies $\omega$, the diagonal elements are equal to one and the off-diagonal elements are small, the system will be approximately decoupled[12].

Considering the static nonlinearity and the coupling characteristic of dynamic linear system, we proposed a new decoupling control strategy for induction motors 
(see Figure 3). In Figure 3, $F(\cdot)$ and $G(\mathrm{z})$ denote the static nonlinear module and dynamic linear module respectively. $D$ is static decoupling matrix, $D^{-1}$ is the inversion of $D . F^{\prime}(\cdot)$ is the product of $F(\cdot)$ and $D^{-1} \cdot N(\cdot)^{-1}$ is the inversion of the nonlinearity of the system. $Q_{1}(\mathrm{z})$ and $Q_{2}(\mathrm{z})$ represent the subsystems of the decoupled system respectively. Based on the decoupling control of the above mentioned linear dynamic system, the dynamic linear module of Hammerstein model can be looked as two independent dynamic sub-linear modules approximately at low frequency domain.

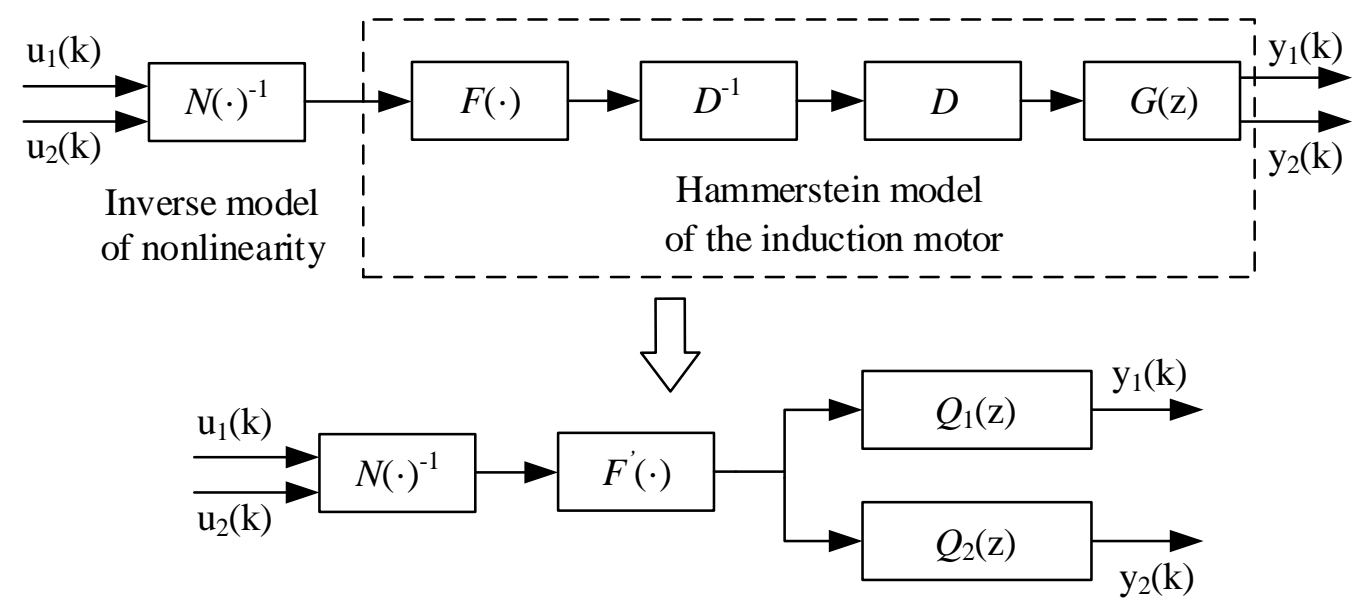

Figure 3. Block Diagram of Decoupling Control Based On Hammerstein Model

\subsection{Identification of Hammerstein Motor}

\subsubsection{Identification of the Linear Module}

Induction motors have low pass property. So the dynamic linear module of the Hammerstein model of induction motors can be looked as two independent dynamic linear modules for simplicity. The dynamic linear module of Hammerstein model can be can be identified using the step response[13]. In Figure 2, $v(\mathrm{k})$ and $u(\mathrm{k})$ were varied synchronously[14]. If $u(\mathrm{k})$ is a step signal, $v(\mathrm{k})$ is a synchronous step signal. In the identification, we assumed that the steady-state gains of two dynamic linear modules were both equal to 1 for convenience.

An induction motor powered by a voltage source inverter has two inputs ( $u_{\mathrm{sm}}$ and $\left.u_{\mathrm{st}}\right)$ and two outputs $\left(\omega_{\mathrm{r}}\right.$ and $\left.\Psi_{\mathrm{r}}\right)$. Giving the input $u_{\mathrm{sm}}$ and $u_{\mathrm{st}}$ step signals, then speed linear model can be identified using ARMA model according to the corresponding response. And the rotor flux linear model can be obtained using ARMA model in the same way[14].

\subsubsection{Identification of the Static Nonlinear Module}

Static NN can be used to approximate the inversion of the static nonlinearity of induction motors. In this work, three layers NN inverse model was adopted. The excitation function of hidden neurons is monotonic smooth hyperbolic tangent function:

$$
f(x)=\frac{\mathrm{e}^{2 x}-\mathrm{e}^{-2 x}}{\mathrm{e}^{2 x}+\mathrm{e}^{-2 x}}
$$

The ouput layer is composed of neurons with linear threshold excitation functions. The connection weights of the $\mathrm{NN}$ can be optimized on inputs and outputs 
of an induction motor collected offline. The exciting signal of the system should be reasonable. The minimum step of the exciting signal is set to 4 seconds to guarantee the stability of an induction motor system[15]. The exciting signals of the induction motor are shown in Figure 4(a) and the response signal is shown in Figure 4(b).

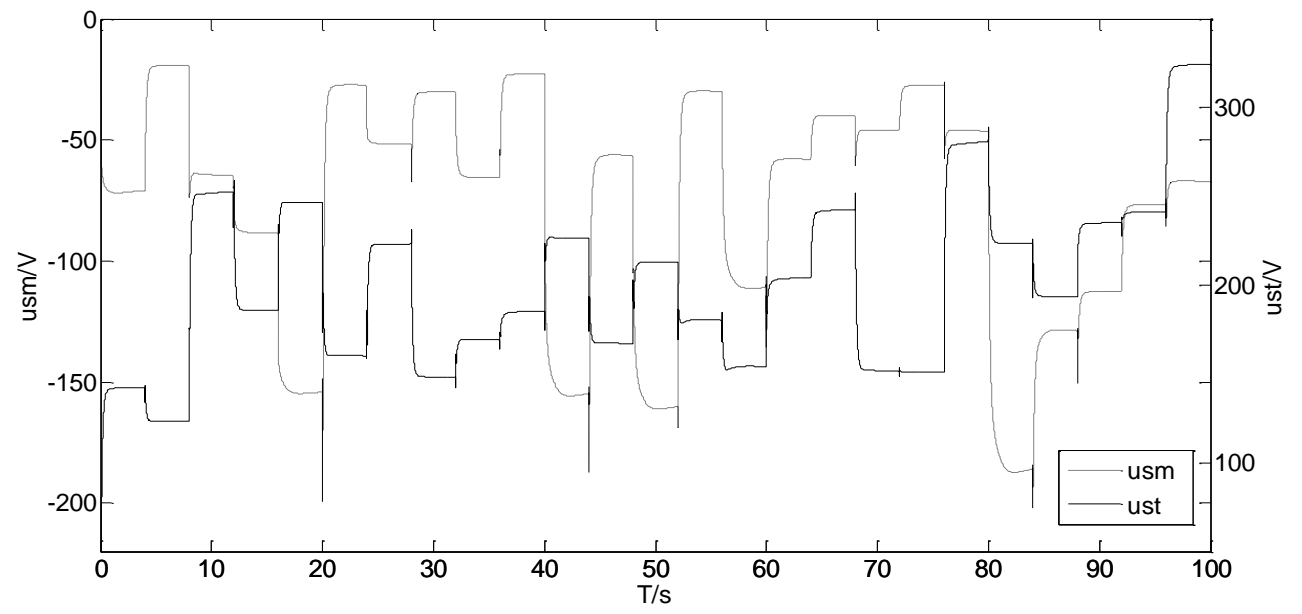

(a) Exciting signals of $u_{\mathrm{sm}}$ and $u_{\mathrm{st}}$

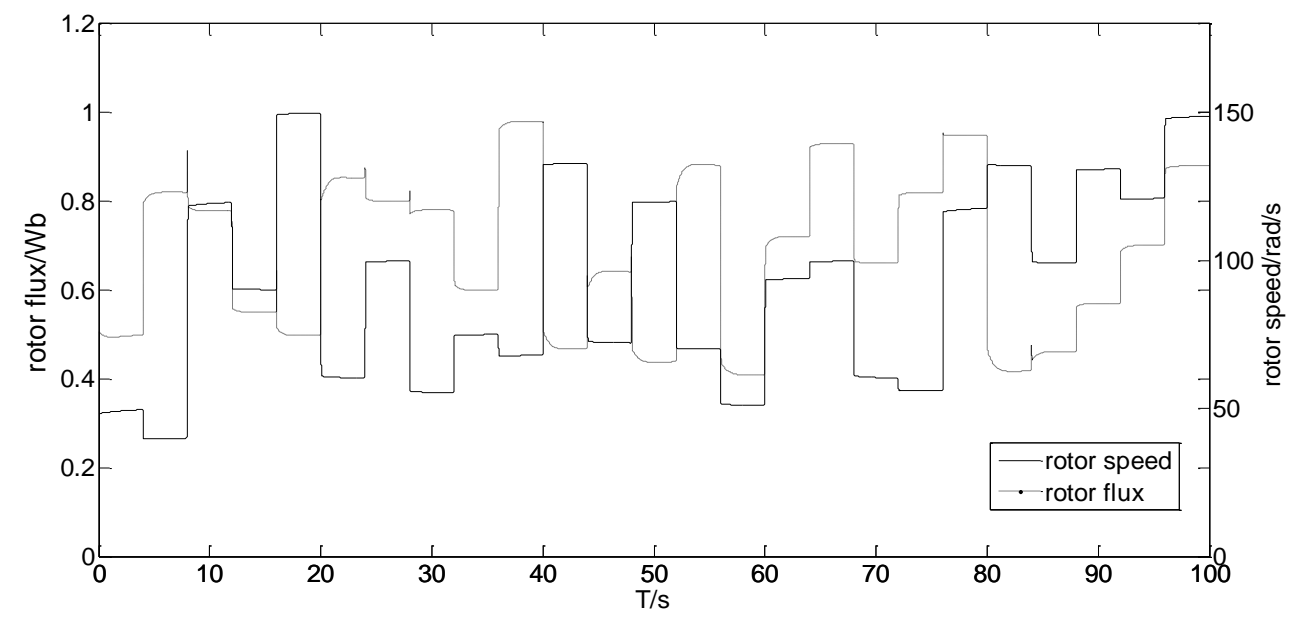

(b) Response signals of $\omega_{\mathrm{r}}$ and $\psi_{\mathrm{r}}$

Figure 4. Input and Output Signals of an Induction Motor for Identification

\subsection{Inversion of Static Nonlinear Module}

For the aim of control, NN inverse model is used to offset the nonlinear characteristic of an induction motor system in the framework of the Hammerstein model. Cascading the neural network inverse model with an induction motor, the original system can be looked as approximate pseudolinear systems. The strategy of data collection for training $\mathrm{NN}$ inverse model in the framework of the model reference adaptive control is presented in Figure 5. In the scheme, exciting signals was given to the induction motor and the Hammerstein model at the same time. And the errors $\left(e_{1}\right.$ and $\left.e_{2}\right)$ between the outputs of two models were used to design an objective function to optimize connection weights of static NN module by the gradient descent method. Finally, the NN inverse model can be achieved on the static data collected from inputs $u_{\mathrm{sm}}, u_{\mathrm{st}}$ and outputs $v_{1}, v_{2}$ of the trained NN nonlinear model offline. 


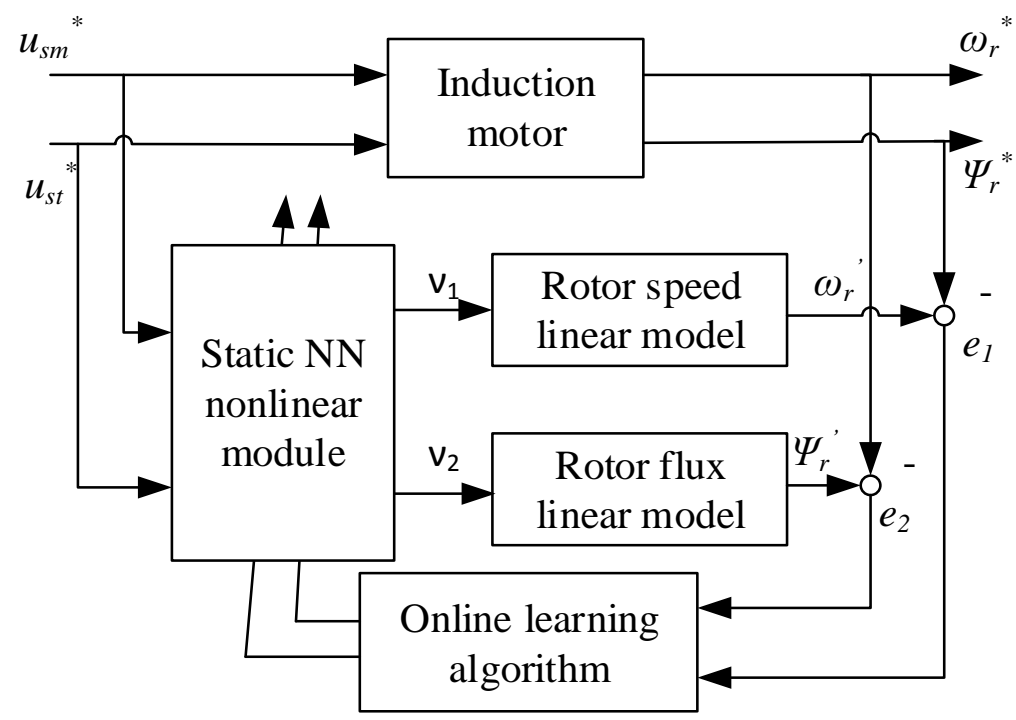

Figure 5. Block Diagram of Training Neural Network Inverse Model

\subsection{Static Decoupling Control Strategy for Induction Motors}

The NN inverse model used to compensate the nonlinearity of induction motors is cascaded with the original plant. The newly-formed system can be viewed as approximate pseudolinear systems consisting of a rotor speed linear subsystem and a rotor flux linear subsystem. The approximate pseudolinear systems are shown in Figure 6 . The speed regulator and the rotor flux regulator were employed for closeloop control. The two regulators are both PI controller. The close-loop control structure is presented in Figure 7.

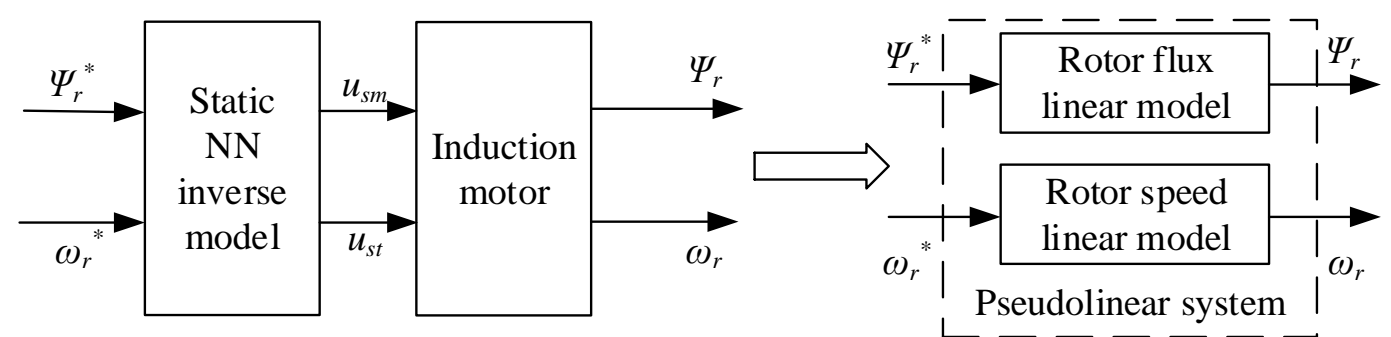

Figure 6. Structure of Approximate Pseudolinear Systems 


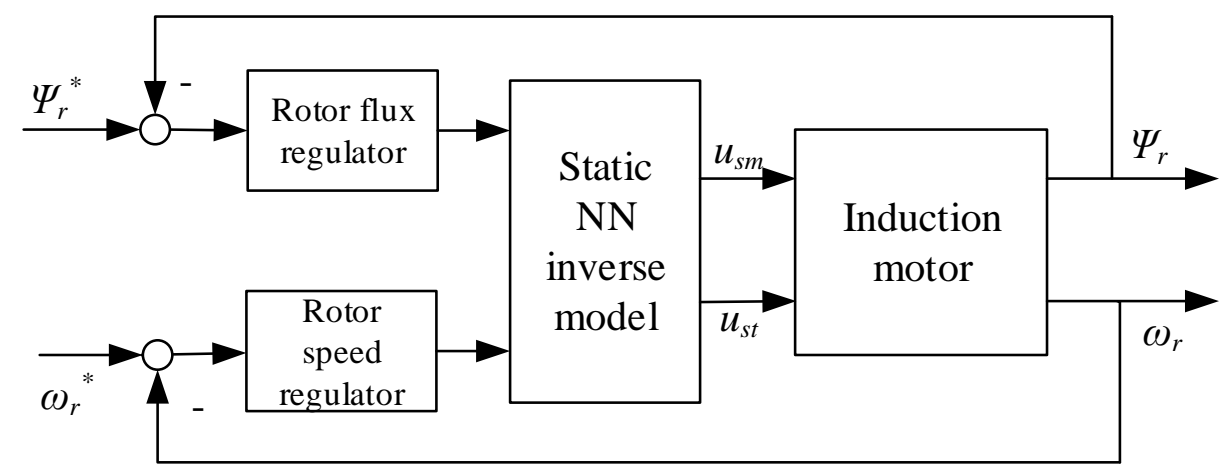

\section{Figure 7. Block Diagram of Static Decoupling Control Based On Hammerstein Model for an Induction Motor}

\section{Simulations}

\subsection{Parameters of the Three Phase Induction Motor}

In this simulation, the three-phase induction motor with squirrel cages was investigated. Its parameters are as follows: nominal power $P_{\mathrm{e}}$ and nominal voltage $U_{\mathrm{e}}$ are $1.1 \mathrm{~kW}$ and $220 / 380 \mathrm{~V}$ respectively. The rated speed is $1400 \mathrm{r} / \mathrm{min}$. The number of pole-pairs $n_{\mathrm{p}}$ is 2 . The stator resistance $R_{\mathrm{s}}$ and inductance $L_{\mathrm{s}}$ are $5.9 \Omega$ and $0.574 \mathrm{H}$ respectively. The rotor resistance $R_{\mathrm{r}}$ and the inductance $L_{\mathrm{r}}$ are $5.6 \Omega$ and $0.58 \mathrm{H}$ respectively. The mutual inductance $L_{\mathrm{m}}$ is $0.55 \mathrm{H}$ and the inertia $J$ is $0.0021 \mathrm{kgm} m^{2}$.

\subsection{Dynamic Linear Module}

The rotor speed linear model and the rotor flux linear model of the induction motor were obtained as equation (14) and equation (15) respectively using the method in section 3.2.1.

$$
\begin{gathered}
Q_{1}(\mathrm{z})=\frac{0.0037312 z+0.0037312}{z^{2}-0.495042 z-0.49749} \\
Q_{2}(\mathrm{z})=\frac{0.11896 z+0.11896}{z^{2}-0.36674 z-0.39533}
\end{gathered}
$$

\subsubsection{Decoupling Control with Rated Load}

The control performance of the proposed static decoupling system with rated load is shown in Figure 8. The dynamics of rotor flux decreases from $0.96 \mathrm{~Wb}$ to $0.8 \mathrm{~Wb}$ at $t=5 \mathrm{~s}$ in Figure $8(\mathrm{a})$. The dynamics of rotor speed increases from $100 \mathrm{rad} / \mathrm{s}$ to $120 \mathrm{rad} / \mathrm{s}$ at $\mathrm{t}=8 \mathrm{~s} . K_{\mathrm{P}}$ and $K_{\mathrm{I}}$ of the flux regulator and the speed regulator are both equal to 2 and 20 respectively. Figure 8 shows that the responses of the flux and the speed follow their corresponding references closely. 


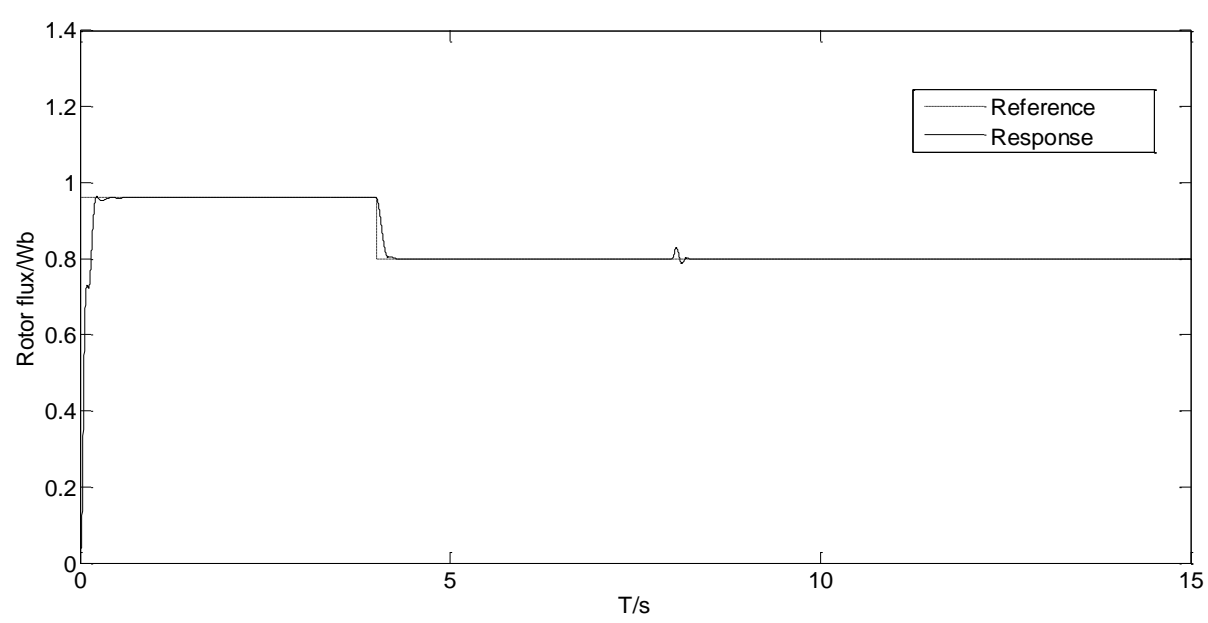

(a) Input and response of the rotor flux

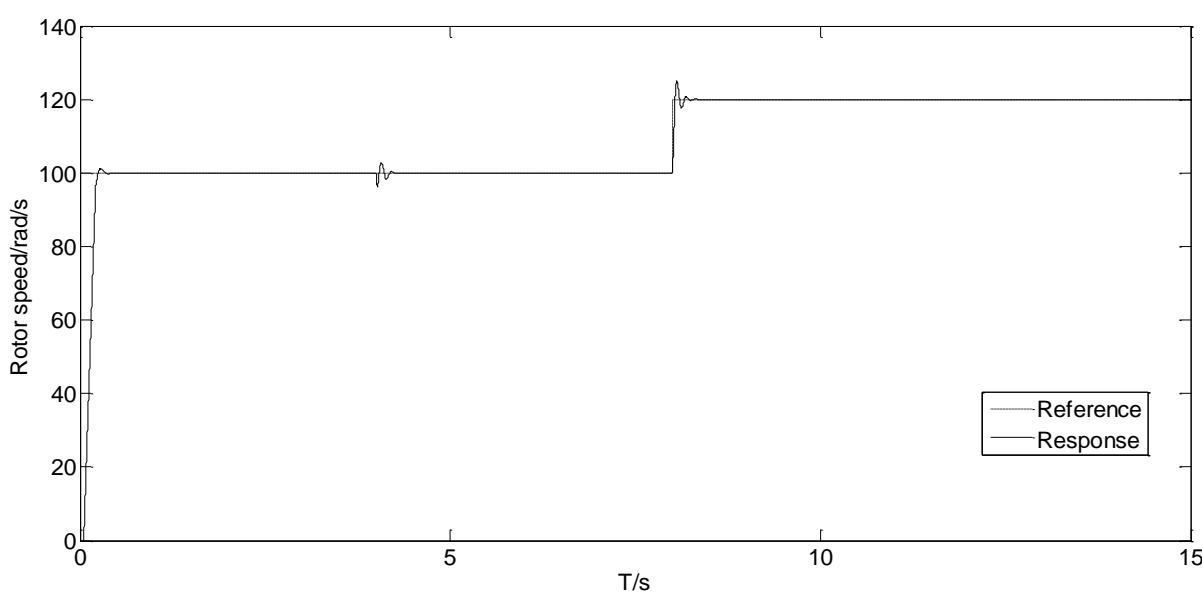

(b) Input and response of the rotor speed

Figure 8. Dynamics of the Decoupling Control System with Rated Load

\subsubsection{Decoupling Control with Load Variation}

Load variation was also investigated in this work to evaluate the robustness of the proposed static decoupling control method. The rotor speed and the flux change as those in section 4.2.1. The induction motor started with rated load $7.5 \mathrm{Nm}$. Then, the load decreased to $5 \mathrm{Nm}$ at $\mathrm{t}=2 \mathrm{~s}$ and increases to $8 \mathrm{Nm}$ at $\mathrm{t}=12 \mathrm{~s} . \mathrm{K}_{\mathrm{P}}$ and $K_{\mathrm{I}}$ of the flux regulator are 1.2 and 18 respectively; $K_{P}$ and $K_{I}$ of the speed regulator are 2 and 20 respectively. Simulations show that load variation can affect the rotor speed and the flux responses transiently and the responses can converge to the corresponding references quickly (see Figure 9). The results indicate that the proposed static decoupling control system has good robustness to load variation. 


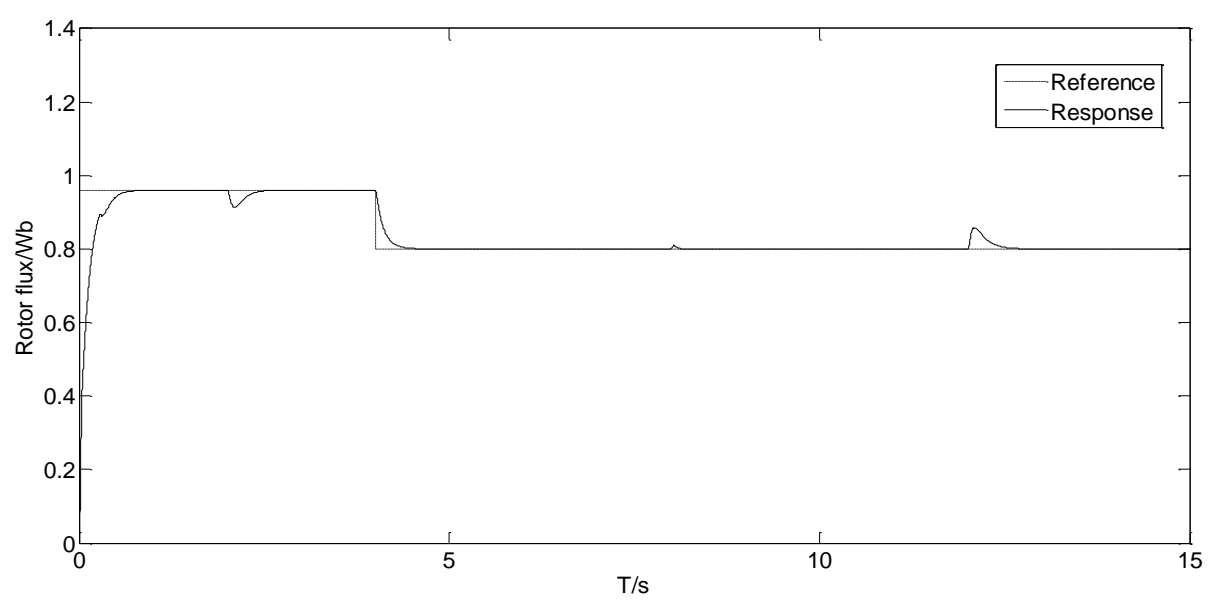

(a) Input and response of the rotor flux system

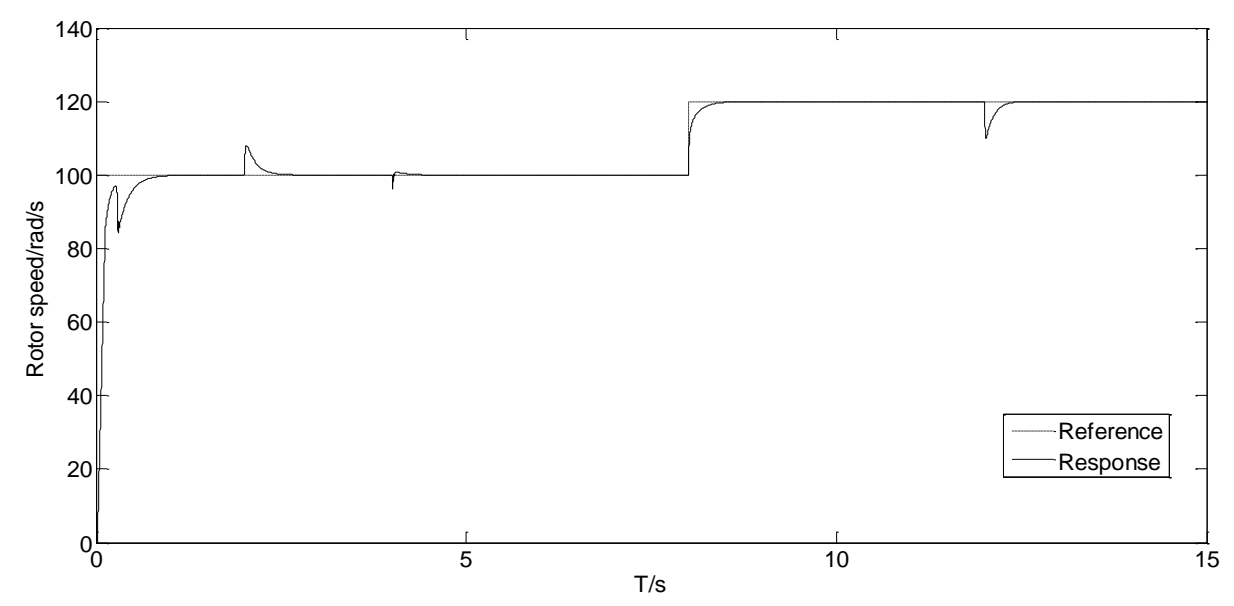

(b) Input and response of the rotor speed system

Figure 9. Dynamics of Decoupling Control System with Load Variation

\subsubsection{Comparisons of Different Decoupling Control Strategies}

The comparisons of the proposed decoupling control strategy and the NN a-order inverse decoupling control strategy[6] with rated load are shown in Figure 10. Both decoupling control strategies employ PI controllers. The parameters of the flux regulator and the speed regulator in the proposed decoupling control strategy are $K_{\mathrm{P}}=2, K_{\mathrm{I}}=20$, and the parameters of the flux regulator and the speed regulator in the $\mathrm{NN} \alpha$-order inverse decoupling control strategy are $K_{\mathrm{P}}=13.3, K_{\mathrm{I}}=1.7$. The rotor speed and the flux change as those in section 4.2.1. From Figure 10, it can be observed that the control performance of the proposed static decoupling control strategy is better than that of the $\mathrm{NN} \alpha$-order inverse decoupling control strategy considering overshoot and setting time. 


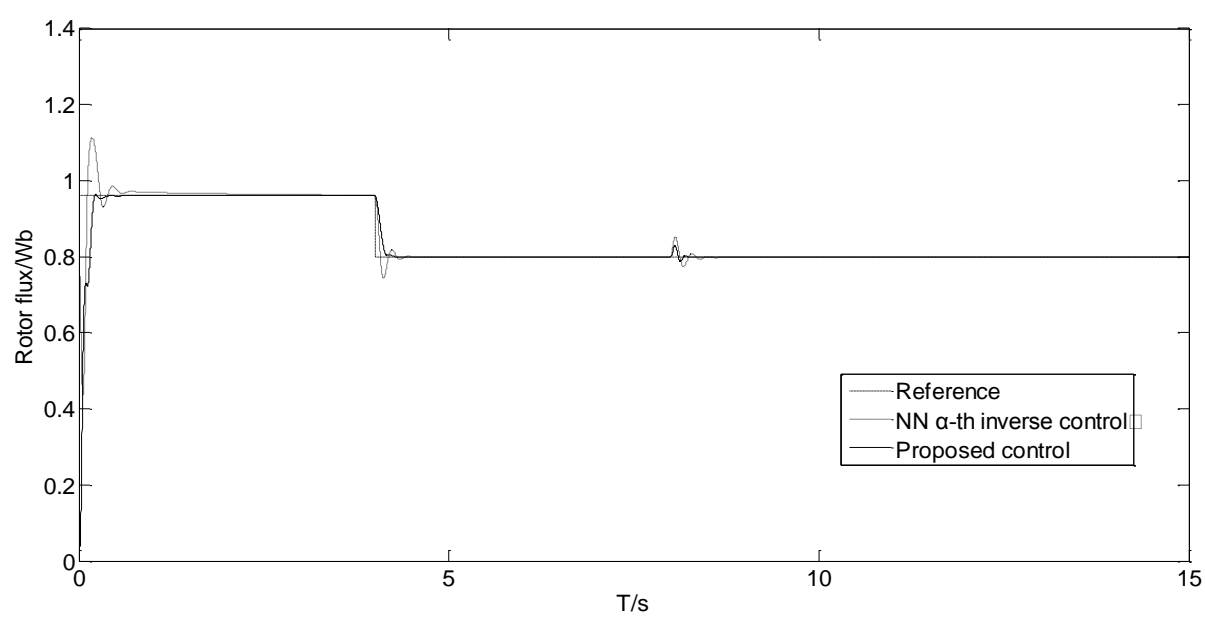

(a) Response comparisons of the rotor flux

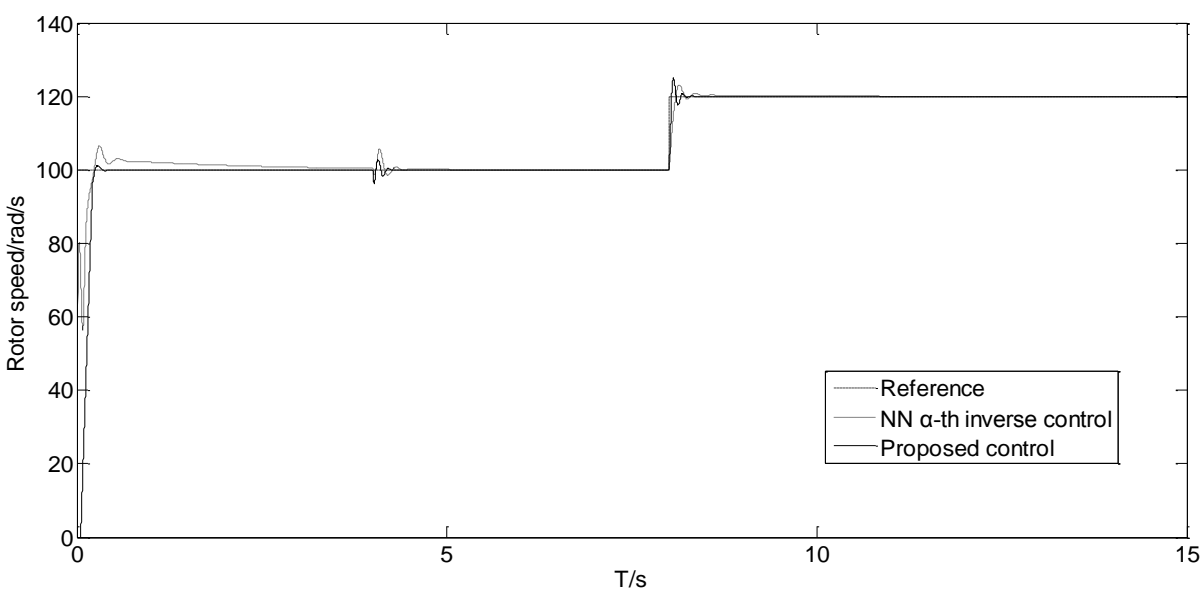

(b) Response comparisons of the rotor speed

Figure 10. Comparisons of Different Decoupling Control Strategies with Rated Load

\section{Conclusions}

A new static decoupling control strategy based on Hammerstein model and NN for induction motors was proposed. In the method, a systematic method of training static decoupling inversion based on $\mathrm{NN}$, used to decouple induction motors approximately, was developed. Through the inversion, an induction motor can be decoupled into two independent linear systems approximately. In nature, the coupling characteristic of the induction motor is offset by the NN inversion. Simulations show that the proposed control strategy has high performance of decoupling control for induction motors without/with load variation in close loop control.

\section{References}

[1] C. Chan, W. Leung and C. Ng, "Adaptive decoupling control of induction motor drives", IEEE Transactions on Industrial Electronics, vol. 37, no.1, (1990), pp. 41-47.

[2] Y. Kawabata, T. Kawakami, Y. Sasakura, E. C. Ejiogu and T. Kawabata, "New design method of decoupling control system for vector controlled induction motor", IEEE Transactions on Power Electronics, vol.19, no.1, (2004), pp. 1-9.

[3] J. Chiasson, "Dynamic feedback linearization of the induction motor", IEEE Transactions on Automatic Control, vol. 38, no.10, (1993), pp. 1588-1594. 
[4] X. Dai, D. He, X. Zhang and T. Zhang, "MIMO system invertibility and decoupling control strategies based on ANN ath-order inversion", IEE Proceedings-Control Theory and Applications, vol.148, no.2, (2001), pp. 125-136.

[5] X. Dai, G. Liu, H. Zhang and X. Zhang, "Neural network inverse control of variable frequency speedregulating system in V/F mode", 31st Annual Conference of the IEEE Industrial Electronics Society, New York, USA,(2005), pp.1701-1706.

[6] X. Dai, X. Zhang, G. Liu and L. Zhang, "Decoupling control of induction motor based on neural networks inverse", Proceedings of the CSEE, vol. 24, no. 1, (2004), pp. 112-117.

[7] G. Liu, K. Yu and W. Zhao, "Neural network based internal model decoupling control of three-motor drive system", Electric Power Components and Systems, vol. 40, no. 14, (2012), pp. 1621-1638.

[8] X. Liu, X. Zhang, J. Hu, Y. Liu, G. Liu and L. Zhao, "Three-motor synchronous decoupling control based on BP neural network", in Control and Decision Conference, Guilin, China,(2009), pp. 5365-5368.

[9] K. Narendra and P. Gallman, "An iterative method for the identification of nonlinear systems using a Hammerstein model", IEEE Transactions on Automatic Control, vol. 11, no. 3, (1966), pp. 546-550.

[10] H. Tajima, G. Guidi and H. Umida, "Consideration about problems and solutions of speed estimation method and parameter tuning for speed-sensorless vector control of induction motor drives", IEEE Transactions on Industry Applications, vol. 38, no. 5, (2002), pp. 1282-1289,.

[11] W. Xiang, J. Sheng and Z.-H. Chen, "Model predictive control based on neural networks for Hammerstein type nonlinear systems", "Journal of Graduate School of the Chinese Academy of Sciences, vol. 25, no. 2, (2008), pp. 224-232.

[12] K. J. Åström, K. H. Johansson and Q.-G. Wang, "Design of decoupled PI controllers for two-by-two systems", IEE Proceedings-Control Theory and Applications, vol. 149, (2002), no.1, pp.74-81.

[13] Y. Zhu, "Multivariable system identification for process control: Elsevier", Netherlands, (2001).

[14] J.-C. Jeng and H.-P. Huang, "Nonparametric identification for control of MIMO Hammerstein systems", Industrial \& Engineering Chemistry Research, vol. 47, no.17, (2008), pp. 6640-6647.

[15] K. H. Chan, J. Bao and W. J. Whiten, "Identification of MIMO Hammerstein systems using cardinal spline functions", Journal of Process Control, vol.16, no.7, (2006), pp. 659-670. 